\title{
Does caffeine reduce methotrexate intolerance in patients with rheumatoid arthritis: a randomized controlled study
}

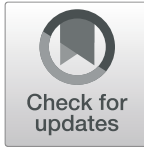

Fatma H. EL Nouby ${ }^{1 *}$, Nihal Ahmed Fathi ${ }^{2}$, Amal Abdelaziz Fehr ${ }^{3}$, Abdel-Azim Assi ${ }^{4}$, Reem Mahmoud Lotfy ${ }^{1}$ and Samar H. Goma $2^{2^{*}}$ (D)

\begin{abstract}
Background: Intolerance to MTX is the most common cause of non-compliance that leads to poor disease control. Treatment is usually discontinued due to intolerance which interferes with compliance of the patient to long-term treatment. Caffeine causes most of its biological effects via antagonizing all types of adenosine receptors (ARs). Our aim was to investigate the effect of caffeine intake on reducing symptoms of MTX intolerance in patients with RA.

Methods: Ninety patients were diagnosed as RA with MTX intolerance divided into 2 groups. Sixty patients were prescribed caffeine or dark chocolate. Control group included 30 patients who will continue MTX regimen without addition of any extra caffeine.

Results: Group A (caffeine group): There was no statistically significant difference between patients and controls at the start of the study. There was statistically significant decrease in methotrexate intolerance severity score (MISS) all over the study period $(P=0.001$ ), and also MISS was statistically significantly lower in each follow-up time when compared with time $0(P=0.001)$.

Group B (control group): There was statistically significant increase in MISS all over the study period $(P=0.017)$; also, MISS was statistically significantly higher in follow-up time 2 and time 3 when compared with time $0(P=0.033)$. We found that after 3 months, $80 \%$ of group A patients showed complete relief, 6.7\% showed partial relief, 10\% showed minimal relief, and $3.3 \%$ got worse.

Conclusion: Adding caffeine to management regimen can reduce the symptoms of MTX intolerance in RA patients. Caffeine relieved the symptoms of MTX intolerance in $80 \%$ of RA patients after 3 months of adding caffeine to management regimen.
\end{abstract}

Keywords: Rheumatoid arthritis (RA), Caffeine, Methotrexate intolerance

\section{Background}

Rheumatoid arthritis (RA) is an autoimmune chronic inflammatory arthritis affecting about 5 per 1000 of the adult general population worldwide with disease onset at any age (peak at 55 years) and 2 to 3 times higher incidence in

\footnotetext{
* Correspondence: fatmanoby@yahoo.com; samarhassanein2010@yahoo.com 'Department of Rheumatology, Physical Medicine and Rehabilitation, Aswan University, Aswan 81528, Egypt

2Department of Rheumatology, Physical Medicine and Rehabilitation, Assiut University, Asyut 71515, Egypt

Full list of author information is available at the end of the article
}

women than men [1]. Despite the development of many types of therapies for RA in recent years, methotrexate (MTX) has remained anchor disease-modifying antirheumatic drugs (DMARD) for most patients since the late 1980s because of its potent efficacy; however, despite its long-term and widespread use for RA, the precise mechanism of this drug remains unknown [2]. Nearly $20-30 \%$ of RA patients stopped MTX because of MTX intolerance within the first year of therapy [3]. Intolerance to MTX is the most common cause of non-compliance leading to poor

\section{Springer Open}

(0) The Author(s). 2020 Open Access This article is licensed under a Creative Commons Attribution 4.0 International License, which permits use, sharing, adaptation, distribution and reproduction in any medium or format, as long as you give appropriate credit to the original author(s) and the source, provide a link to the Creative Commons licence, and indicate if changes were made. The images or other third party material in this article are included in the article's Creative Commons licence, unless indicated otherwise in a credit line to the material. If material is not included in the article's Creative Commons licence and your intended use is not permitted by statutory regulation or exceeds the permitted use, you will need to obtain permission directly from the copyright holder. To view a copy of this licence, visit http://creativecommons.org/licenses/by/4.0/. 
disease control. MTX intolerance symptoms may be categorized as:

1. Gastrointestinal symptoms including nausea, abdominal cramps, bloating, pain, discomfort, heaviness, acidity, epigastric distress, loose motions, or constipation [4]

2. Behavioral symptoms including anticipatory symptoms such as anxiety, aversion to MTX name, seeing or thinking of ampule, depression, aversion to food, unpleasant taste and odors, insomnia, headaches, and difficulty in concentration

3. Nonspecific symptoms including fatigue, loss of appetite, the whole body feeling hot, and burning in the chest [5]

The adenosine signaling pathway is the leading hypothesis to explain the efficacy of methotrexate in RA patients. Adenosine can be formed intracellularly from ATP and exported from the cell, but the majority of adenosine is formed extracellularly by sequential dephosphorylation of ATP to adenosine in the extracellular space [6].

Methylxanthines (e.g., caffeine, cocoa, and theophylline) act as adenosine receptor antagonists in humans. MTX acts by increasing extracellular adenosine. This means that caffeine causes most of its biological effects via antagonizing all types of adenosine receptors (ARs) [7]. Methylxanthines reverse MTX effect by preventing the nucleoside from acting on receptors [4].

Our aim was to investigate the effect of caffeine intake on reducing symptoms of MTX intolerance in patients with RA.

\section{Methods}

This is a prospective, randomized controlled study conducted at Aswan University Hospital, Aswan, Egypt from May 2018 till May 2019. Ninety patients diagnosed as RA according to 2010 American College of Rheumatology/European League Against Rheumatism (ACR-EULAR) classification criteria for RA [8] attending the outpatient clinic were enrolled in the study. All of patients experienced moderate to severe MTX intolerance according to methotrexate intolerance severity score (MISS). Written informed consent was obtained from all study participants. Study was approved by Ethical Medical Committee of Faculty of Medicine, Aswan University, Aswan, Egypt according to the guidelines of the Helsinki Declaration.

Patients less than 18 years, patients drinking $>4$ cups caffeine/day (> $548 \mathrm{mg}$ /day as each cup contains $137 \mathrm{mg}$ according to the US Department of Agriculture food) [9, 10], patients with renal or hepatic impairment, and pregnant women were excluded from the study.
The disease activity in RA patients was assessed by the 28 joint count Disease Activity Score (DAS 28) using the number of swollen and tender joints, erythrocyte sedimentation rate (ESR), and patient's global status, and pain was evaluated by the visual analog scale (VAS) range from 0 to $100 \mathrm{~mm}$ [11].

Group A: Sixty patients were prescribed caffeine (coffee or dark chocolate) as an antidote to MTX intolerance according to the schedule used in Malaviya's study and was described below [4].

Coffee schedule for non-coffee-drinking patients: One to one and half teaspoon of powdered "instant coffee" (containing 30-45 mg caffeine) prepared in 160 to $200 \mathrm{ml}$ water (taken with or without milk, with or without sugar) synchronized with MTX weekly dose. Regimen of coffee was prescribed three times during MTX weekly dose as follow: the first dose to be taken with breakfast, the second in the evening 1-3 $\mathrm{h}$ before MTX dose, and the last dose at the next day morning. This amount of coffee would be equivalent to 90 to $135 \mathrm{mg}$ of caffeine over $24 \mathrm{~h}$.

For coffee-drinking patients: the above schedule was added to the cups taken by the patient on the day of MTX administration.

Dark chocolate: Patients who did not like coffee or dark chocolate will be advised as follows: to take "four squares" (40 gm) of the most popular brand of "dark chocolate," i.e., if MTX intolerance persisted, they will be free to take another $40 \mathrm{~g}$ of chocolate after $8-12 \mathrm{~h}$. This amount would be equivalent to 88 to $176 \mathrm{mg}$ of caffeine over $24 \mathrm{~h}$ [4].

Group (B): The control group included 30 patients who will continue MTX regimen without addition of any extra caffeine.

\section{Study protocol}

The patient characteristics such as age, gender, the duration of MTX treatment, the period after which MTX intolerance began, and dose/route of MTX at which symptoms of intolerance appeared were documented. The methotrexate intolerance severity score (MISS) was evaluated at base line before initiation of therapy, then at the next 3 months consecutively. The details of the various medications and other measures used for the control of symptoms of MTX-intolerance were also recorded. These included antiemetics, antacids, protonpump inhibitors, sugar candy, and plain sugar. Both groups were prescribed with folic acid supplements in a dose of one tablet $(500 \mathrm{mcg})$ each day except on the day of injection.

\section{MTX intolerance severity score}

The initial MISS questionnaire contained 16 items divided into 5 domains, including abdominal pain 
(stomach ache), nausea, vomiting, oral pain (sore mouth), and behavioral symptoms. The first 4 domains contained 3 items each, related to adverse effects after MTX intake as well as anticipatory and associative adverse effects. The fifth domain, on behavioral symptoms, included restlessness, crying, irritability, and refusal of MTX. On each item, a patient could score 0 (no symptoms), 1 point (mild symptoms), 2 points (moderate symptoms), or 3 points (severe symptoms). MTX intolerance was defined as $\geq 6$ points, including at least one anticipatory, associative, or behavioral symptom [12]. The MTX intolerance was classified into: (i) "Minimal" or "Mild," if patients were able to manage it by themselves in the various ways including taking sugar candy or plain sugar, adjusting the MTX timing; (ii) moderate, when the patients required antiemetics/antacids, dose/route of adjustment (including shifting from oral to parenteral route) in addition to antiemetics and antacids; (iii) "Severe," if the patient was inclined to discontinue MTX despite these measures; MISS was repeated at each follow-up visit [4].

\section{Grading of the response to caffeine}

1) Complete relief: if symptoms of MTX-intolerance improved so that the anti-emetic and other drugs for its control were discontinued.

2) Partial relief: if the symptoms were better, but antiemetics/antacids were still needed.

3) Minimal relief: if there was no improvement of symptoms.

4) Worse: if caffeine caused similar aversion as did MTX [4].

\section{Statistical methods}

All analyses were performed using the SPSS software (version 24.0; SPSS Inc., Chicago, IL). $P$ values of $\leq$ 0.05 will be deemed to indicate statistical significance. The pretreatment and posttreatment outcomes were compared by using the paired $t$ test for quantitative data and the Mc Nemar test for qualitative data. The two groups were compared by using an independent samples $t$ test for quantitative data and the 2 tests for qualitative data. Screening for extreme values in quantitative variables was done by using independent student $t$ test and repeated measures ANOVA test with Bonferroni post hoc test. Discrete and categorical variables were screened by using frequency distribution and Fisher's exact test.

\section{Results}

Ninety patients were enrolled in the current study (Fig. 1).
Our results showed that the mean age was $48.6 \pm 10.6$ years in group A (caffeine group) in comparison to 45.6 \pm 12.7 in group B (control group). The percentage of male to female was equal in both groups. Twenty percent of group A has medical history of hypertension versus $10 \%$ in group B. Four patients were diabetic in group A in comparison to two patients in group B. There was no statistically significant difference between the two studied groups regarding these variables ( $P$ values 0.324 , 1.000, 0.402 respectively) (Table 1 ).

As regards DAS-28, mean \pm SD was $4.28 \pm 1.62$ and $4.97 \pm 1.4$ for groups $A$ and $B$, respectively, with no significant difference between the two groups during the follow-up period ( $P$ value 0.476$)$.

\section{MTX prescription data}

The mean duration of MTX treatment was $38.3 \pm$ 48.5 and $30.5 \pm 32.0$ months in groups $\mathrm{A}$ and $\mathrm{B}$, respectively. The mean duration since the onset of MTX intolerance was $19.5 \pm 18.5$ for group A and $18.3 \pm 17.7$ months for group B. The mean dose of MTX in groups A and B were $15.4 \pm 4.3$ and $14.7 \pm$ $3.9 \mathrm{mg}$ per week, respectively. Most patients in both groups received their doses of MTX subcutaneously (93.3\%, 86.7\%). There was no statistically significant difference between the two studied groups regarding these variables $(P$ values $0.467,0.798,0.345$, and 0.671 , respectively) (Table 2 ).

\section{MTX intolerance severity score}

Group A: There was statistically significant decrease in the mean MISS score all over the study period $(P=$ 0.001 ) except for time 0 where $P$ value was 0.202 , and the mean MISS score was statistically significantly lower in each follow-up time when compared with time $0(P=$ 0.001 ).

Group B: There was statistically significant increase in MISS all over the study period $(P=0.017)$, and also MISS was statistically significantly higher in follow-up time 2 and time 3 when compared with time $0(P=$ 0.033) (Fig. 2, Table 3).

Figure 3 shows the effect of caffeine on MTX intolerance in group A all over the study period. We found that at time $3,80 \%$ of patients showed complete relief, $6.7 \%$ showed partial relief, $10 \%$ showed minimal relief, and $3.3 \%$ worsen.

\section{Discussion}

Caffeine is a known antagonist of adenosine receptor. Inhibition of these receptors in the CNS may thus improve MTX intolerance. Hypothetically, this could also reduce the noxious effects of MTX on inflammation as adenosine receptors are involved in its therapeutic action [13]. 


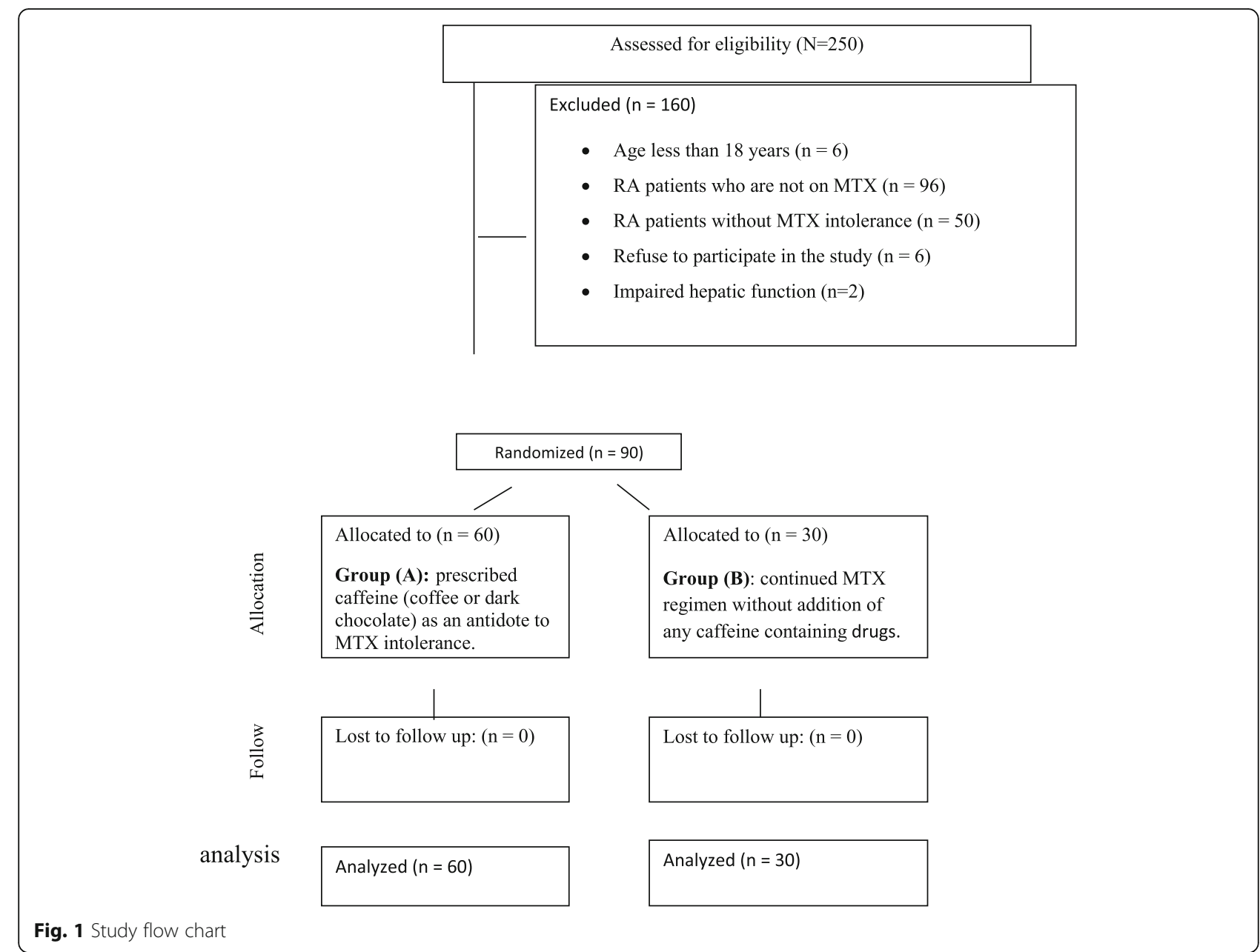

The main finding of this study was that adding caffeine to management regimen can reduce the symptoms of severe MTX intolerance in RA patients. Caffeine relieved the symptoms of severe MTX intolerance in $80 \%$ of patients after 3 months so much that the antiemetic and other drugs were discontinued. While $6.7 \%$ showed partial improvement of symptoms during the same period but the antiemetic and other drugs were still needed, $10 \%$ showed minimal improvement of symptoms, and 3.3\% reported worsening of symptoms and stopped caffeine.

Our study came in accordance with a study on 120 RA patients whom had moderate or severe MTX intolerance when added caffeine; $55 \%$ had complete relief of symptoms and were able to continue taking the MTX, while 13.3\% had partial improvement and continued taking MTX with antiemetics; $7.5 \%$ were minimally better but were somehow managing, and $10 \%$ were complete

Table 1 Demographic data of two studied groups

\begin{tabular}{|c|c|c|c|c|}
\hline Demographic variable & & Group A $(n=60)$ & Group B $(n=30)$ & $P$ value \\
\hline \multirow[t]{2}{*}{ Age } & Mean \pm SD & $48.6 \pm 10.6$ & $45.6 \pm 12.7$ & 0.324 \\
\hline & Range & $26-60$ & $18-65$ & \\
\hline \multirow[t]{2}{*}{ Gender no (\%) } & Male & $8(13.3 \%)$ & $4(13.3 \%)$ & 1.000 \\
\hline & Female & $52(86.7 \%)$ & $26(86.7 \%)$ & \\
\hline \multirow[t]{3}{*}{ Medical history no (\%) } & None & $44(73.3 \%)$ & $26(86.7 \%)$ & 0.402 \\
\hline & Hypertension & $12(20 \%)$ & $3(10 \%)$ & \\
\hline & Diabetes & $4(6.7 \%)$ & $2(3.3 \%)$ & \\
\hline
\end{tabular}


Table 2 Comparison between the two studied groups regarding MTX prescription data

\begin{tabular}{|c|c|c|c|c|}
\hline Demographic variable & & Group A $(n=60)$ & Group B $(n=30)$ & $P$ value \\
\hline \multirow[t]{2}{*}{ MTX duration (month) } & Mean \pm SD & $38.3 \pm 48.5$ & $30.5 \pm 32.0$ & 0.467 \\
\hline & Range & $4-168$ & $1-120$ & \\
\hline \multirow[t]{2}{*}{ MTX intolerance duration (month) } & Mean \pm SD & $19.5 \pm 18.5$ & $18.3 \pm 17.7$ & 0.798 \\
\hline & Range & $3-60$ & $1-60$ & \\
\hline \multirow[t]{2}{*}{ Dose of MTX(mg) } & Mean \pm SD & $15.4 \pm 4.3$ & $14.7 \pm 3.9$ & 0.345 \\
\hline & Range & $12.5-17.5$ & $12.5-17.5$ & \\
\hline \multirow[t]{2}{*}{ Route of administration $n(\%)$} & IM & $4(6.7 \%)$ & $4(13.3 \%)$ & 0.671 \\
\hline & SC & $56(93.3 \%)$ & $26(86.7 \%)$ & \\
\hline \multirow[t]{4}{*}{ Medications to control intolerance $n(\%)$} & None & $12(20 \%)$ & $6(20 \%)$ & 0.532 \\
\hline & Pantoprazole & $48(80 \%)$ & $21(70 \%)$ & \\
\hline & Antiemetics & $0(0 \%)$ & $1(3.3 \%)$ & \\
\hline & Pantoprazole + antiemetics & $0(0 \%)$ & $2(6.7 \%)$ & \\
\hline
\end{tabular}

caffeine failure without any relief. The significant relief with a schedule of coffee intake synchronized with MTX has urged the recommendation that adult patients with RA and MTX intolerance should drink "a few cups more coffee" on the day of MTX administration [4].

Another study done included a total of 410 patients; 396 (96.58\%) with RA, 4 (0.97\%) with spondyloarthritis and $10(1.21 \%)$ others (undifferentiated connective tissue diseases, systemic lupus erythematosus Sjogren's). The severity of the intolerance was measured on a score $0-100$ numeric. Of the 410 patients, $212(51.7 \%)$ had minimal MTX intolerance so that no intervention was required. One hundred ninety-eight $(48.29 \%)$ patients had moderate-severe MTX intolerance and was advised to take strong coffee on the day of MTX-dose as follows: two cups early in the morning, another two cups $2-3 \mathrm{~h}$ before the dose of MTX taken late in the evening. A 3rd dose of two cups was repeated the next morning with breakfast. They found that $15.15 \%$ of patients had complete relief, $7.57 \%$ had $70-95 \%$ relief of symptoms, and $44.94 \%$ had $10-60 \%$ relief of symptoms [14].
A study was performed on 115 RA patients who had moderate or severe MTX intolerance. Among these, 52 (45.2\%) had complete relief of symptoms with the addition of caffeine; 17 (14.8\%) had partial improvement and continued taking MTX but only with antiemetic; 14 (12.2\%) were minimally better but were somewhat managing; $14(12.2 \%)$ did not get any relief and discontinued MTX [15].

Another study published in 2017, authors concluded that caffeine relieved the symptoms of MTX intolerance in $56 \%$ and gave partial relief in another $13 \%$ of the patients [4].

Some authors suggested that caffeine may interfere with MTX efficacy. Nesher et al. conducted a study on 39 RA patients; they were divided in 3 groups; each group had different amount of caffeine intake (low < $120 \mathrm{mg} /$ day, medium $120-180 \mathrm{mg} /$ day, and high $>180 \mathrm{mg} /$ day). They concluded that caffeine, in daily amounts $>180 \mathrm{mg}$, interferes with the efficacy of MTX in patients with RA, when compared with patients consuming < $120 \mathrm{mg} /$ day [16]. Another study published in 2006 on 264 RA patients, authors

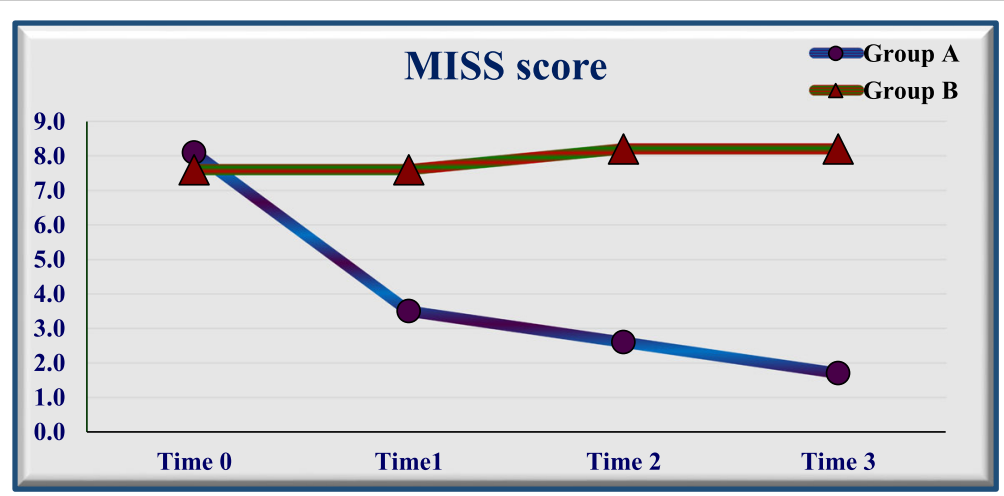

Fig. 2 Comparison between the two study groups regarding MISS score 
Table 3 Comparison between the two studied groups regarding MISS score

\begin{tabular}{llll}
\hline MISS score & & Group A $(n=60)$ & Group B $(n=30)$ \\
\hline Time 0 (baseline) & Mean \pm SD & $8.1 \pm 1.5$ & $7.6 \pm 1.3$ \\
& Range & $6-12$ & $6-10$ \\
Time 1 (after 1 month) & Mean \pm SD & $3.5 \pm 7.9$ & $7.9 \pm 1.3$ \\
& Range & $0-9$ & $6-11$ \\
Time 2 (after 2 months) & Mean \pm SD & $2.6 \pm 2.5$ & $8.2 \pm 1.5$ \\
& Range & $0-9$ & $6-12$ \\
Time3 (after 3 months) & Mean \pm SD & $1.7 \pm 2.3$ & $8.2 \pm 1.5$ \\
& Range & $0-9$ & $6-12$ \\
P0 & & $0.001^{*}$ \\
P1 & & $0.001^{*}$ & $0.017^{*}$ \\
P2 & & $0.001^{*}$ & 0.053 \\
P3 & $0.001^{*}$ & $0.033^{*}$ \\
\hline PP & & $0.033^{*}$ \\
\hline
\end{tabular}

$P P$ value for independent student $t$ test for comparison between the two studied groups, $P O P$ value for repeated measures ANOVA test for comparison in between the same group, $P 1 P$ value for Bonferroni post hoc test between time 0 and time 1 in the same group, $P 2 P$ value for Bonferroni post hoc test between time 0 and time 2 in the same group, $P 3 P$ value for Bonferroni post hoc test between time 0 and time 3 in the same group

conclude that high caffeine consumption does not affect methotrexate efficacy, compared with low and moderate caffeine consumption [5]. This is in accordance to our study as we found no significant difference between the two groups during follow-up period which means that this caffeine dose did not interfere with MTX efficacy.

Our study has some advantages. First, we used natural coffee in the intervention group, and this augmented patient satisfaction due to avoidance of multiple chemicals that was needed to control MTX intolerance. Second, in contrast to previous studies which have included all degrees of MTX intolerance, our study included moderate to severe MTX intolerance. This allows precise evaluation and decreases bias. Third, we used MISS score for evaluation and follow-up of patients during treatment period which allowed to provide greater precision, which translates to greater statistical power to detect response to treatment. Lastly, the dose of caffeine was calculated and prepared by the observer which achieved more precise and accurate dose of caffeine.

There were some limitations in the study. First, sample size was small and larger studies are still needed to ensure replicability. Second, MTX intolerance was assessed subjectively using the available MISS with no available another objective tool that could provide more accurate information. Lastly, to avoid the limitation of inability to be sure of patient's adherence, a suggestion that could help in future similar studies is that to try to follow adherence of patients to coffee drinking using diaries in which

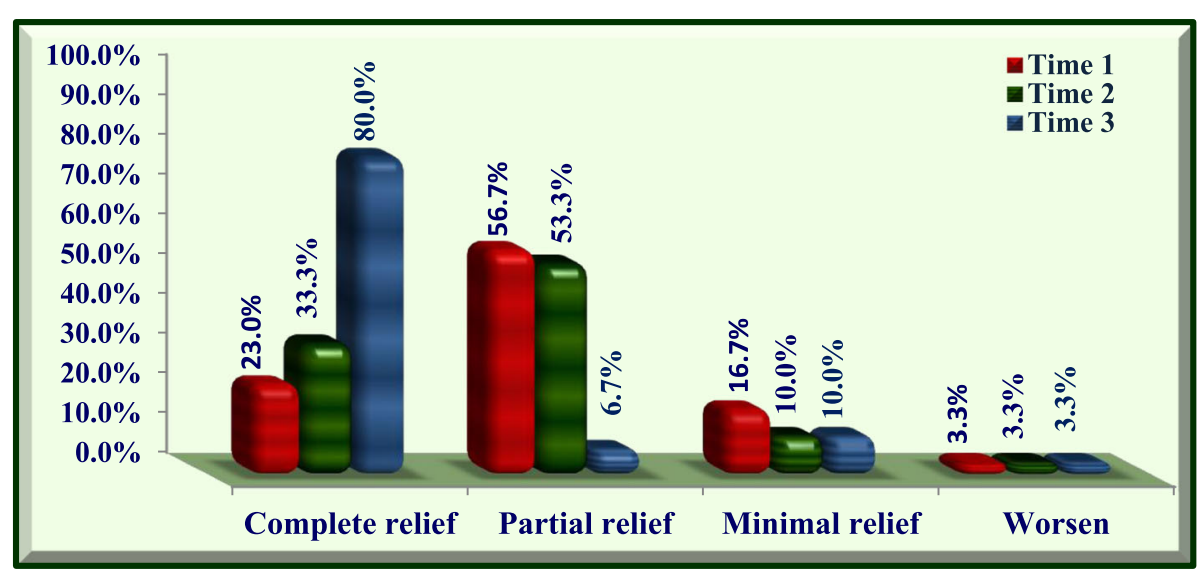

Fig. 3 Distribution of the effect of caffeine on MTX intolerance in caffeine group all over the study period 
patients record their intake, and this can be reviewed by the authors during the follow-up visits which will give a feedback about adherence.

\section{Conclusion}

Adding caffeine to management regimen can reduce the symptoms of severe MTX intolerance in RA patients. Caffeine relieved the symptoms of severe MTX intolerance in $80 \%$ of patients after 3 months of adding caffeine to management regimen.

\section{Abbreviations}

RA: Rheumatoid arthritis; MTX: Methotrexate; ARs: Adenosine receptors; MISS: Methotrexate Intolerance Severity Score

\section{Acknowledgements}

Not applicable.

\section{Authors' contributions}

Dr. FE, AF, and RL shared the conceptualization, study design, clinical work, investigations, formal analysis, and revised the written paper. Prof. NF, SG, and AA shared also conceptualization, the study design, writing the paper, conducting the results and formal analysis. All authors have read and approved the manuscript. Dr. SG was responsible for paper submission.

\section{Funding}

No funding was received for this work.

\section{Availability of data and materials}

All data and materials are available on request.

\section{Ethics approval and consent to participate}

Study was approved by Ethical Medical Committee of Faculty of Medicine, Aswan University according to the guidelines of the Helsinki Declaration (Aswu/192/12/17). All patients gave informed written consent.

\section{Consent for publication}

All participants of the study approve the submission.

\section{Competing interests}

All authors declare no conflict of interest.

\section{Author details}

'Department of Rheumatology, Physical Medicine and Rehabilitation, Aswan University, Aswan 81528, Egypt. ²Department of Rheumatology, Physical Medicine and Rehabilitation, Assiut University, Asyut 71515, Egypt.

${ }^{3}$ Department of Rheumatology, Physical Medicine and Rehabilitation, Helwan University, Helwan, Egypt. ${ }^{4}$ Department of Pharmacology, Assiut University, Asyut, Egypt.

Received: 5 May 2020 Accepted: 26 June 2020

Published online: 19 October 2020

\section{References}

1. Nogueira E, Gomes A, Preto A, Cavaco-Paulo A (2016) Update on therapeutic approaches for rheumatoid arthritis. Curr Med Chem 23(21): 2190-2203

2. Friedman B, Cronstein B (2019) Methotrexate mechanism in treatment of rheumatoid arthritis. Jt Bone Spine 86(3):301-307

3. Wang W, Zhou H, Liu L (2018) Side effects of methotrexate therapy for rheumatoid arthritis: a systematic review. Eur J Med Chem 158:502-516

4. Malaviya AN (2017) Methotrexate intolerance in the treatment of rheumatoid arthritis (RA): effect of adding caffeine to the management regimen. Clin Rheumatol 36(2):279-285

5. Benito-Garcia E, Heller JE, Chibnik LB, Maher NE, Matthews HM, Bilics JA et al (2006) Dietary caffeine intake does not affect methotrexate efficacy in patients with rheumatoid arthritis. J Rheumatol 33(7):1275-1281
6. Cronstein BN, Sitkovsky M (2017) Adenosine and adenosine receptors in the pathogenesis and treatment of rheumatic diseases. Nat Rev Rheumatol 13(1):41-51

7. Ribeiro JA, Sebastiao AM. Caffeine and adenosine. J Alzheimers Dis 2010; 20(s1):S3-15.

8. Aletaha D, Neogi T, Silman AJ, Funovits J, Felson DT, Bingham CO III et al (2010) 2010 rheumatoid arthritis classification criteria: an American College of Rheumatology/European League Against Rheumatism collaborative initiative. Arthritis Rheum 62(9):2569-2581

9. Pichlmeier U, Heuer KU (2014) Subcutaneous administration of methotrexate with a prefilled autoinjector pen results in a higher relative bioavailability compared with oral administration of methotrexate. Clin Exp Rheumatol 32(4):563-571

10. Li W, Han J, Qureshi AA. No association between coffee and caffeine intake and risk of psoriasis in US women. Vol. 148, Archives of dermatology. United States; 2012. p. 395-7.

11. Wells G, Becker JC, Teng J, Dougados M, Schiff M, Smolen J et al (2009) Validation of the 28-joint Disease Activity Score (DAS28) and European League Against Rheumatism response criteria based on C-reactive protein against disease progression in patients with rheumatoid arthritis, and comparison with the DAS28 based on erythr. Ann Rheum Dis 68(6):954-960

12. Bulatović M, Heijstek MW, Verkaaik M, van Dijkhuizen EHP, Armbrust W, Hoppenreijs EPA et al (2011) High prevalence of methotrexate intolerance in juvenile idiopathic arthritis: development and validation of a methotrexate intolerance severity score. Arthritis Rheum 63(7):2007-2013

13. Alarcón GS (2006) Does caffeine intake affect methotrexate efficacy?: Commentary. Nat Clin Pract Rheumatol 2(11):592-593

14. Baghel S, Verma S, Thakran MA, Ravita MC (2019) Use of coffee for alleviating methotrexate intolerance in rheumatic diseases. Indian J Rheumatol 14(1):79

15. Cabrera M, Villarreal L, Buitrago-Garcia D, Santos-Moreno P. SAT0744-HPR prevalence of commorbidities in patients with rheumatoid arthritis and correlation with disease activity and type of therapy. 2018;1832.2-1833.

16. Nesher G, Mates M, Zevin S (2003) Effect of caffeine consumption on efficacy of methotrexate in rheumatoid arthritis. Arthritis Rheum 48(2):571572

\section{Publisher's Note}

Springer Nature remains neutral with regard to jurisdictional claims in published maps and institutional affiliations.

\section{Submit your manuscript to a SpringerOpen ${ }^{\circ}$ journal and benefit from:}

- Convenient online submission

- Rigorous peer review

- Open access: articles freely available online

High visibility within the field

- Retaining the copyright to your article

Submit your next manuscript at $\boldsymbol{\nabla}$ springeropen.com 